\title{
Prospective memory and aging: preserved spontaneous retrieval, but impaired deactivation, in older adults
}

\author{
Michael K. Scullin • Julie M. Bugg • \\ Mark A. McDaniel • Gilles O. Einstein
}

Published online: 10 May 2011

(C) Psychonomic Society, Inc. 2011

\begin{abstract}
Prospective remembering is partially supported by cue-driven spontaneous retrieval processes. We investigated spontaneous retrieval processes in younger and older adults by presenting prospective memory target cues during a lexical decision task following instructions that the prospective memory task was finished. Spontaneous retrieval was inferred from slowed lexical decision responses to target cues (i.e., intention interference). When the intention was finished, younger adults efficiently deactivated their intention, but the older adults continued to retrieve their intentions. Levels of inhibitory functioning were negatively associated with intention interference in the older adult group, but not in the younger adult group. These results indicate that normal aging might not compromise spontaneous retrieval processes but that the ability to deactivate completed intentions is impaired.
\end{abstract}

Keywords Memory Aging · Interference/inhibition in memory retrieval $\cdot$ Directed forgetting

Portions of this project were presented at the 51st Annual Meeting of the Psychonomic Society, St. Louis, MO. We are appreciative to Laura Cobb for her assistance in data collection and analysis and to Rachel Scullin and Katie Arnold for their help in conducting research leading up to this project. J.M.B. was supported by National Institute on Aging Grant 5T32AG00030.

M. K. Scullin $(\bowtie) \cdot J$. M. Bugg $\cdot$ M. A. McDaniel Department of Psychology, Washington University in St. Louis, St. Louis, MO 63130-4899, USA

e-mail: mscullin@wustl.edu

G. O. Einstein

Department of Psychology, Furman University,

Greenville, SC 29613, USA
Prospective memory refers to remembering to perform an intended action in the future, such as remembering to feed the dog before leaving for work and remembering to deliver a message to a colleague. Because a great deal of each day is spent forming and executing intentions, it is no surprise that, by some estimates, at least half of everyday forgetting is due to prospective memory failures (Crovitz \& Daniel, 1984). Good prospective memory may be especially important for older adults, who often have health-related prospective memory demands, such as remembering to take medication.

In the typical event-based prospective memory task (e.g., Einstein \& McDaniel, 1990), while participants are busily engaged in an ongoing task, they also have an intended action to perform in the context of that task. Specifically, they might be asked to rate the imageability of nouns (the ongoing task) and also to remember to press the "Q" key whenever a target word (e.g., corn) appears (the prospective memory task). Successful prospective remembering requires that one switch from seeing corn as an item to be processed for the ongoing task to seeing it as a cue for performing a prospective memory action. In contrast to typical explicit retrospective memory tasks such as cued recall, a critical characteristic of a prospective memory task is that the experimenter does not prompt the participant to engage in a memory search when the target cue occurs.

An important issue is how prospective memory changes with age. Research on age differences in prospective memory has yielded a mixed pattern of results (see Henry, MacLeod, Phillips, \& Crawford 2004, for a meta-analysis), with some studies showing minimal or no age differences on a prospective memory task (e.g., Cherry \& LeCompte, 1999; Einstein \& McDaniel, 1990; Kvavilashvili, Kornbrot, Mash, Cockburn, \& Milne 2009) and others showing robust age-related declines on a prospective memory task (Maylor, 
1996; West, Herndon, \& Covell 2003). In an attempt to explain this variability, Kliegel, Jager, and Phillips (2008) conducted a meta-analysis and reported that age-related prospective memory performance differences are smaller when performance can be augmented by spontaneous retrieval processes (as is theorized to be the case with focal prospective memory tasks; see Einstein \& McDaniel, 2005). Spontaneous retrieval processes are argued to be stimulus-triggered (by strongly associated environmental cues), such that retrieval may require that no resources be devoted to maintaining the prospective memory intention prior to processing the associated cue (Harrison \& Einstein, 2010; McDaniel \& Einstein, 2007; Scullin, McDaniel, \& Einstein 2010b; Scullin, McDaniel, Shelton, \& Lee, 2010c).

Two processes have been proposed to account for spontaneous retrieval (McDaniel, Guynn, Einstein, \& Breneiser, 2004). On the basis of Moscovitch's (1994) view of the hippocampal system, if a target cue and a prospective memory intention are strongly associated, full processing of the target will reflexively bring to mind the associated prospective memory intention (reflexive-associative hypothesis; see McDaniel et al., 2004). For example, in a prospective memory task, if the target corn and the intended action of pressing the "Q" key are strongly associated in memory, later processing of the word corn can spontaneously bring the intended action of pressing the "Q" key to mind. Spontaneous retrieval may also be supported by a discrepancy-plus-attribution process, which is based on Whittlesea and Williams's (2001a, 2001b) theory that we constantly evaluate the processing quality of target information (note that this evaluation process is considered to be a chronic cognitive process that is not specific to prospective memory and, therefore, should not be equated with prospective memory monitoring). As a result of thinking about the target item during encoding, when we later encounter the item, we may spontaneously notice a discrepancy in the processing quality or fluency of the target (relative to other items), eliciting (possibly) an attribution of significance. That attribution may then stimulate a memory search to determine the item's significance (Breneiser \& McDaniel, 2006).

A provocative idea in the prospective memory literature is that older adults sometimes perform as well as younger adults on prospective memory tasks (Kliegel et al., 2008) because spontaneous retrieval processes are preserved in normal aging (McDaniel \& Einstein, 2000; see also Einstein, McDaniel, \& Scullin, in press; McDaniel \& Einstein, in press). The view that spontaneous retrieval processes should be preserved in older adults is consistent with Craik's (1986) theory that aging compromises capacity-demanding retrieval processes that demand selfinitiation, but not those in which good environmental cues can trigger retrieval.
To provide a direct test of spontaneous retrieval that does not depend on executing a prospective memory response, Einstein et al. (2005, Experiment 5) developed a new prospective memory paradigm (see also Cohen, Dixon, \& Lindsay 2005 , for a similar paradigm developed to examine script intentions). In one example of this paradigm, participants were given the prospective memory task to remember to press the "Q" key when the word dancer appeared in the context of an image-rating task (Scullin, Einstein, \& McDaniel 2009). Participants were then informed that they would need to perform the prospective memory task during a later image-rating task, but not until after performing a lexical decision task. Critically, the word dancer still appeared during the lexical decision task. Because participants did not need to perform the prospective memory task during the lexical decision task, they did not monitor for the cues or maintain the intention in awareness (Knight et al., 2011; Marsh, Hicks, \& Cook 2006; Scullin, McDaniel, \& Einstein 2010b). A characteristic of spontaneous retrieval is that it occurs without intention; thus, the occurrence of the word dancer was expected to produce (spontaneous) retrieval of intentionrelated information, which would be revealed by slowed lexical decision responding to the target (relative to control) words. This intention interference effect (Cohen et al., 2005), which has been observed reliably in younger adults (Einstein et al., 2005; Knight et al., 2011; McDaniel \& Scullin, 2010; Scullin et al., 2009), suggests that some aspect of the prospective memory intention was spontaneously noticed, detected, or retrieved when the target cue was processed.

In a paradigm modified from the one just described, Scullin et al. (2009) gave younger adults a prospective memory task to perform during an image-rating phase and then either instructed them that they would have to perform the task again at a later time (suspended condition) or told them that their prospective memory task was completed (finished condition). Then participants performed a lexical decision task, during which the prospective memory target words (and control words) still appeared. If intention interference simply reflects familiarity to cues (i.e., slowing that results from recognizing familiar items), one might expect no effect of the suspended versus finished condition. However, in contrast to the familiarity hypothesis, intention interference was observed in the suspended condition, but not in the finished condition. The results could also not be explained by differences in monitoring, because there were no differences across conditions in control trial response latencies. These results suggest that younger adults deactivate (or otherwise efficiently forget) finished intentions. In the present experiment, we extended Scullin et al.'s (2009) finished paradigm to test whether older adults also quickly deactivate their prospective memory intentions. 
The cognitive aging literature suggests an age-related deficit in the ability to deactivate non-task-related processes, which can lead to difficulty in suppressing distraction by irrelevant information (Grady, Spinger, Hongwanishkul, McIntosh, \& Winocur 2006). Along these lines, the inhibitory deficit hypothesis (Hasher \& Zacks, 1988) argues that an important function of inhibition is to delete no longer relevant information and that this ability declines with age (Lustig, Hasher, \& Zacks 2007). One intriguing prediction for the present experiment is that the older adults (relative to the younger adults) will continue to spontaneously retrieve their prospective memory intentions during the final lexical decision phase, even though doing so is no longer necessary or relevant. To examine whether the intention interference effect (i.e., here, the spontaneous retrieval of finished intentions) is related to inhibitory control, we administered measures of inhibition and executive control (the Stroop task and the trail-making test; see, e.g., De Frias, Dixon, \& Strauss 2009; Dempster, 1992; Langenecker, Zubieta, Young, Akil, \& Nielson 2007; Spieler, Balota, \& Faust 1996). According to the hypothesis that intention interference reflects familiarity to cues, rather than associative retrieval, intention interference should not be related to inhibitory measures, and both younger and older adults should demonstrate intention interference for finished intentions.

One additional parallel with the Scullin et al. (2009) finished procedure is worth mentioning. To investigate the role of delay (cf. Hicks, Marsh, \& Russell 2000; Scullin \& McDaniel, 2010) between intention completion and the later intention-interference phase, we included two phases of an image-rating task prior to the lexical decision task and manipulated whether the prospective memory task was encoded (and performed) during the first or second image-rating phase. Participants who performed the prospective memory task during the first phase (longerdelay condition) experienced a longer delay between learning that the prospective memory task was finished and seeing their target words again (during the lexical decision task) than did those who performed the prospective memory task during the second phase (shorter-delay condition). Delay-group differences in intention interference were not observed, perhaps because the younger adults could quickly deactivate finished intentions (Scullin et al., 2009). We included this delay manipulation in the present experiment to determine whether the previous null findings could be replicated for younger adults and whether there would be an effect of delay for the older adults. If older adults have only some difficulty deactivating finished intentions, a longer delay may help to reduce intention interference. Alternatively, if the age-related difficulty with deactivating irrelevant tasks is substantial (Grady et al., 2006; Lustig et al., 2007), the longer delay may not help older adults.

\section{Method}

Participants Forty Washington University undergraduates $\left(M_{\text {age }}=20.38\right.$ years, $\left.S D=1.48\right)$ participated for partial class credit or monetary compensation. Thirty-eight older adults $\left(M_{\text {age }}=75.95\right.$ years, $\left.S D=7.39\right)$ were recruited from Washington University's older adult participant pool and were provided monetary remuneration. Participants were tested in groups of 1-4.

Design The experiment was a $2 \times 2 \times 2$ mixed factorial design, in which we varied age (younger, older) and delay (longer, shorter) between subjects and lexical decision task item (target, control) within subjects. We were interested in prospective memory performance during an initial imagerating phase, lexical decision response latencies to target and control words, and performance on measures of inhibition (Stroop task, trail-making test).

Procedure The prospective memory and intention interference procedure was identical to that in the finished condition used by Scullin et al. (2009). Participants performed three successive image-rating phases, a lexical decision task phase, and, finally, the Stroop and the trailmaking tasks. Participants were told that all of their responses on the computerized tasks should be made using the same hand.

First, participants received instructions for the imagerating task. They were told to rate words on their imageability by pressing the " 1 ," " 2 ," or " 3 " key on the number pad, with " 1 " indicating easy to image (e.g., tooth), "3" indicating difficult to image (e.g., truth), and "2" indicating somewhere in between. The instructions were followed by a block of image-rating practice trials that contained a pair of control words (the pair that was not given as the target).

Participants in the longer-delay condition next received a pair of target words (either fish and writer or corn and dancer) and were instructed to press the "Q" key when they saw a target word during the image-rating task. The target/ control word pairs were matched on number of letters, number of syllables, and frequency (using the Kučera \& Francis, 1967, norms) and were counterbalanced across conditions such that when corn and dancer were targets, fish and writer were controls (and vice versa). Participants were asked to repeat the prospective memory instructions to the experimenter, and they were verbally reminded that their primary goal was to respond to the image-rating task. They then performed another block of practice trials that included one presentation of each target word (they were expected to press the "Q" key during this phase). Following the prospective memory practice block, participants in the longer-delay condition filled out a demographics form and 
completed a vocabulary test (Mill Hill; Raven, Raven, \& Court, 1988). All participants then performed 80 image-rating experimental trials. The prospective memory target words appeared on trials $15,35,55$, and 75 (longer-delay condition). Following the first image-rating phase, participants in the longer-delay condition were instructed that their prospective memory task was finished and that they would no longer need to remember to press the "Q" key for target words.

In the second image-rating phase, participants in the shorter-delay condition received the prospective memory task instructions and prospective memory task practice trials and filled out forms (demographics, vocabulary) before the experimental image-rating trials (identical in structure to those in the first phase). Following this second phase, participants in the shorter-delay condition were instructed that the prospective memory task was finished. All participants performed a 24-trial image-rating phase before continuing to the lexical decision phase, to ensure that the delay manipulation was not confounded by a difference between conditions in whether they immediately began the lexical decision phase following completion of the prospective memory task.

In the lexical decision task (referred to as the speed task in the experiment), a fixation point appeared on the screen for $500 \mathrm{~ms}$, followed by a string of letters. The string of letters remained on the screen until participants pressed a key labeled "Y" or " $N$ " (the "5" and "6" keys on the number pad, respectively). The instructions emphasized that the participants' sole demand was to decide whether the letters formed a word as quickly and accurately as possible. Then participants explained the lexical decision instructions to the experimenter and practiced the lexical decision task before beginning the 260-trial experimental block. During this lexical decision block, each target word and control word appeared 5 times, and word repetitions were separated by a minimum of 11 trials.

After the lexical decision phase, participants were asked to recall (first) and recognize (second) the target words and response key. As a manipulation check, we also asked participants whether they believed that the prospective memory task was finished following those instructions. In addition, we verbally asked a subset of younger and older participants in which context they were supposed to perform the prospective memory task. All of these participants responded with "image-rating" or "the first task," thereby confirming that the older adults understood the context in which the prospective memory task was to be performed.

Participants next completed paper versions of the Stroop task and trail-making test. For the Stroop task (Golden, 1978; Stroop, 1935), participants first read the names of color words (e.g., red, green, blue) printed in black ink, then named the ink color of XXXX strings printed in red, green, or blue ink, and finally named the ink color of incongruent color words (e.g., the word red printed in blue ink). They were given $45 \mathrm{~s}$ to correctly name as many items as possible in each of these conditions, and the index of inhibition was the number of items participants responded to correctly within $45 \mathrm{~s}$ during the final phase, in which reading of the incongruent word had to be suppressed.

Both components of the trail-making test (A and $\mathrm{B}$ ) (Reitan, 1992) were administered. In trail-making $A$, participants drew lines to connect circles (1-26) in numerical order, as quickly as possible. In trail-making B, both numbers and letters appeared on the page, and participants had to draw a line from number 1 to the first letter (A), then to number 2, then to the second letter (B), and so forth. Time to complete trail-making B was used as the index of inhibition because performance is thought to reflect goal maintenance, task switching, and the ability to inhibit currently irrelevant goals (Langenecker et al., 2007).

Materials The materials were identical to those used by Scullin et al. (2009, Experiment 2). All words in the imagerating task were medium frequency (30-100) words chosen from the Kučera and Francis (1967) norms. The filler (nontarget/noncontrol) items in the lexical decision task were also medium frequency words and contained one to three syllables. The nonwords were constructed from different words by rearranging one or two letters, with the stipulation that they be pronounceable. There were 120 distinct filler items; 40 items appeared once, 40 items appeared twice, and 40 items appeared 3 times. Some items were repeated in order to decrease the relative salience of the target and control words, which were also repeated.

\section{Results}

An alpha level of .05 was set for all analyses. Cohen's $d$ or $\eta^{2}\left(\right.$ not $\left.\eta_{\mathrm{p}}{ }^{2}\right)$ was included as an estimate of effect size wherever a $t$ or $F$ value, respectively, was greater than 1 .

Spontaneous retrieval of a finished intention: Response latencies There were no "Q" responses during the lexical decision phase (commission errors) in the younger and older adult groups. Response latencies on correct target and control items greater than two standard deviations from the mean were trimmed (as in our previous work on intention interference; Einstein et al., 2005; McDaniel \& Scullin, 2010; Scullin et al., 2009). This resulted in the elimination of $4.0 \%$ of the responses. To answer the question of whether participants still retrieved their intentions during the lexical decision phase, we conducted a $2 \times 2 \times 2$ mixed analysis of variance (ANOVA) on mean trimmed response latencies, which included the between-subjects variables of 
age group (younger, older) and delay condition (shorter, longer) and the within-subjects variable of items (target, control) in the lexical decision task. The significant main effects of age group, $F(1,74)=86.50, M S E=22,896.51, \eta^{2}=$ .54 , and target/control item, $F(1,74)=4.93, M S E=1,807.03$, $\eta^{2}=.06$, were qualified by a significant age group $\times$ target/ control item interaction, $F(1,74)=4.55, M S E=1,807.03$, $\eta^{2}=.05$. As is illustrated in Fig. 1, there was no difference in response latencies to target and control items for younger adults (both $M \mathrm{~s}=509 \mathrm{~ms} ; t<1$ ), which was consistent with our previous research showing the absence of intention interference for finished intentions for younger adults (Scullin et al., 2009). More interesting, older adults demonstrated significant intention interference (target, $M=749 \mathrm{~ms}, S D=$ 152; control, $M=720 \mathrm{~ms}, S D=133), t(37)=2.65, d=0.87$, even though their intentions were finished. The main effect of delay and interactions with delay were not significant (all $\left.F_{\mathrm{S}}<1\right)$.

To further investigate age group differences in targetrelated slowing, we examined response latencies to the first presentation of each of the two target words and control words. ${ }^{1}$ Because we expected this analysis to be less powerful than the previous analysis, in which 10 target and 10 control observations were averaged, we elected not to trim responses so as to avoid exacerbating the problem of having a low number of observations. Consistent with the overall analysis, the $2 \times 2 \times 2$ mixed ANOVA, which included the between-subjects variables of age group (younger, older) and delay condition (shorter, longer) and the within-subjects variable of items (target, control) in the lexical decision task revealed a significant age group $\times$ target/control item interaction, $F(1,74)=5.25, M S E=$ $8,379.20, \eta^{2}=.06$ (all other interactions had $F_{\mathrm{S}}<1$ ). There was significant intention interference in the older adult group, $t(37)=3.09, d=1.02$ (target, $M=816 \mathrm{~ms}, S D=203$; control, $M=734 \mathrm{~ms}, S D=138$ ), but not in the younger adult group (target, $M=526 \mathrm{~ms}, S D=124$; control, $M=511 \mathrm{~ms}, S D=$ $99), t(39)=1.06, d=0.34$. Thus, the results were consistent regardless of whether all target and control trials were analyzed or just the first presentation of each word.

Inhibition measures We created a composite measure of inhibition (termed Z-inhibition) by averaging the $Z$-scores for the incongruent Stroop task and trail-making B test, which were strongly correlated, $r(78)=.66$, after transforming the scores on the trail-making B test (multiplying values by -1) so that lower scores on both tasks represented worse inhibitory control. We also generated a composite measure of processing speed (termed Z-speed) by averaging the $Z$-scores for the neutral (XXXX) Stroop color-naming phase (i.e., number of items correctly named in $45 \mathrm{~s}$, which





Fig. 1 Response latencies to target and control words for finished prospective memory intentions and across delay and age groups. Error bars reflect standard errors

reflects processing speed) and the trail-making A phase (transformed in the same manner as trail-making B). These measures were also strongly correlated, $r(78)=.64$. Our primary goals were to examine whether response latencies on the target trials in the lexical decision phase were related to inhibitory control and to evaluate whether inhibitory deficits might explain age differences in the intention interference effect in the present paradigm.

We first aimed to establish that inhibitory functioning was worse in the older adults than in the younger adults. Using the dependent measure of $Z$-inhibition, we conducted an analysis of covariance (ANCOVA) in which age group was a between-subjects variable and $Z$-speed scores were controlled. Consistent with theories that inhibitory/executive function declines with age (e.g., Hasher \& Zacks, 1988; West, 1996), there was a significant effect of age group, $F(1,75)=33.97, M S E=0.19, \eta^{2}=.22$.

Next, we examined whether intention interference during the lexical decision phase was related to inhibitory control by conducting a hierarchical regression analysis using the dependent measure of target trial response latencies. In the first and second steps, we entered control trial response latencies and $Z$-speed composite scores, respectively. In the critical third step, we entered the $Z$-inhibition composite score. The $Z$-inhibition score explained significant additional variance in the older adults, $F(1,34)=4.23$, partial $r=-.33$, but not in the younger adults, $F<1$, partial $r=.04$. This finding indicated that poor inhibitory control was associated with an increase in intention interference in older adults following instructions that the intention was finished.

To examine whether inhibitory control might mediate the observed age differences in intention interference reported above, we conducted a $2 \times 2$ ANCOVA that included age group as a between-subjects variable and target/control item as a within-subjects variable and controlled for the Z- 
inhibition composite scores. Controlling for inhibitory functioning eliminated the age group $\times$ target/control item interaction, $F<1$.

Prospective memory performance A prospective memory response was counted as correct if the participant pressed the "Q" key within two trials of a target word (Scullin, McDaniel, \& Einstein, 2010b) during the image-rating phase. The $2 \times 2$ between-subjects ANOVA that included age group (older or younger adults) and delay (shorter or longer delay) produced no significant effects. Prospective memory performance was high and similar for younger $(M=.87, S D=.29)$ and older $(M=.80, S D=.31)$ adults, $F(1,74)=1.11, M S E=.09, \eta^{2}=.01$. Moreover, there was no effect of delay - that is, whether the prospective memory task was performed during the first $(M=.84, S D=.28)$ or the second $(M=.83, S D=.33)$ image-rating phase, $F<1-$ and no age group $\times$ delay interaction, $F(1,74)=1.23$, $M S E=0.09, \eta^{2}=.02$. One possible concern with concluding that there was no age effect for prospective memory performance was that performance was near ceiling levels. The issue of ceiling effects is a concern for many prospective memory studies (Uttl, 2005). This problem highlights the utility of using an intention interference paradigm to compare spontaneous retrieval in younger and older adults, because intention interference is not limited by ceiling effect concerns.

Postexperimental questionnaire All younger adults and older adults could recall or recognize their target words and target response key (except for one older adult, who could recall only one target word). Furthermore, all participants reported that they believed the experimenter instructions that the prospective memory task was finished.

\section{Discussion}

The central finding of the present research was that older adults, but not younger adults, continued to demonstrate the intention interference effect after learning that their prospective memory task was finished. Intention interference was negatively associated with inhibitory functioning for older adults (inconsistent with a familiarity-to-cues hypothesis and monitoring theory), suggesting that older individuals with poor inhibition were at an increased risk for spontaneously retrieving a finished intention. Furthermore, controlling for inhibitory functioning eliminated age differences in intention interference. These results suggest that inhibition (e.g., the deletion function) or a similar executive control mechanism is required to deactivate or otherwise forget completed intentions and that age-related inhibitory declines may lead to deficits in the ability to "turn off" spontaneous retrieval processes.

Our results support the conclusion that intention interference represents a cue-driven, spontaneous process (Cohen et al., 2005; Einstein et al., 2005; Knight et al., 2011; Scullin et al., 2009) that occurs in the absence of monitoring. There was no incentive to monitor during the lexical decision task (Knight et al., 2011; Marsh et al., 2006), and all participants reported that they understood that the prospective memory task was finished following the image-rating block. Furthermore, the negative correlation between intention interference and the inhibitory composite is inconsistent with a monitoring account of intention interference. The ability to delete (inhibit) no longer relevant information is a critical component of working memory measures (Bunting, 2006; Darowski, Helder, Zacks, Hasher, \& Hambrick 2008; see also Lustig et al., 2007, for a review), and previous work (Smith \& Bayen, 2005) suggests that monitoring is supported by working memory resources. Therefore, from the monitoring perspective, there should have been a positive correlation between our inhibition composite and intention interference. We found exactly the opposite pattern. On a group level, the older adults had both poorer inhibitory control and greater intention interference than did the younger adults. On the individual level, older adults with poorer inhibitory control showed greater intention interference. Thus, rather than indicating continued monitoring during the lexical decision block, it appears that the slowed responding to prospective memory target words during the lexical decision task was due to persistent spontaneous retrieval or spontaneous noticing processes.

Although previous intention interference research has implicated spontaneous retrieval or noticing processes (Einstein et al., 2005; Knight et al., 2011; Scullin et al., 2009), it has remained unclear whether intention interference reflects a reflexive-associative process or a more basic familiarity-to-cues process. The finding of intention interference in the older adults, but not in the younger adults, as well as the association between levels of intention interference and inhibitory functioning supports the view that intention interference does not simply reflect a basic familiarity-to-cues process. At this point, we may only speculate about what participants may be retrieving during the final lexical decision phase. Our most recent work (Scullin, Bugg, \& McDaniel 2010a) on finished intentions demonstrates that older adults make commission errors (i.e., "Q" presses to target words following instructions that the prospective memory task is finished) if there is strong contextual overlap between prospective memory encoding conditions and when the prospective memory target word is presented again. In that situation, we inferred conscious retrieval of the finished prospective 
memory intention. In the present study, there was only a weak (if any) overlap between the prospective memory encoding context (image-rating task) and when the prospective memory target word was presented again (lexical decision task), and no commission errors were observed; therefore, the intention interference may have reflected full spontaneous retrieval or other spontaneous noticing processes (e.g., the target cue elicits a feeling of significance; McDaniel et al., 2004).

In the present work, spontaneous retrieval was assessed following instructions that the prospective memory task was finished, and therefore we predicted that participants would deactivate their intentions or otherwise "turn off" the responsiveness of the spontaneous retrieval mechanism to no-longer-relevant prospective memory cues (Marsh, Hicks, \& Bink 1998; Scullin et al., 2009; West, McNerney, $\&$ Travers 2007). Although the younger adults showed no intention interference in this context (consistent with our previous work; Scullin et al., 2009), the older adults continued to retrieve their prospective memory intentions, as evidenced by the significant slowing on target trials relative to control trials. From one perspective, this result is dramatic and surprising: The older adults showed greater prospective memory retrieval than did the younger adults. However, this increase in spontaneous retrieval is unlikely to be advantageous; retrieving irrelevant intentions may interfere with retrieval of relevant intentions, and perhaps more important, irrelevant retrievals may cause problems in reality monitoring (Hashtroudi, Johnson, \& Chrosniak 1989). For example, if one continues to retrieve the intention to take medication after already doing so, that individual would be at risk for overmedicating, which could be dangerous. Thus, retrieval of finished intentions is likely to represent an age-related impairment, rather than a benefit (as would be the case for a suspended intention).

Why do older adults continue to spontaneously retrieve their intentions when they no longer need to do so (e.g., when an intention is finished)? One possible explanation is that they lack the ability to delete no-longer-relevant information (Lustig et al., 2007). Younger adults may deactivate irrelevant information to reduce interference with current task demands (cf. Anderson, Bjork, \& Bjork's (1994) account of retrievalinduced forgetting), but inhibitory ability might decline in older adults. In the present research, inhibition performance was associated with intention interference such that poor inhibitors demonstrated the greatest evidence for spontaneous retrieval of the finished intention. Furthermore, controlling for inhibitory function eliminated age-related differences in intention interference (i.e., spontaneous retrieval) to finished intentions. Thus, our results support an inhibitory-deficit account of age-related differences in retrieval of finished intentions.

The finding of preserved spontaneous retrieval processes, but impaired intention deactivation processes, in older adults has a number of significant theoretical and practical implications. Although there are robust age differences on most memory tasks (Park et al., 2002), previous research has shown minimal or no age differences on tests with high environmental support (Craik, 1986). The present research extends this work to spontaneous associative memory processes. At first blush, the finding of preserved spontaneous retrieval may seem to be at odds with the prevailing theory that older adults have associative binding and/or retrieval deficits (e.g., NavehBenjamin, 2000); however, our results are consistent with recent research showing minimal, if any age-related decline in associative recollection when good retrieval cues are present and few strategic processes are required (as would be the case with a reflexive-associative spontaneous retrieval process; see Cohn, Emrich, \& Moscovitch 2008). Thus, contrary to the popular view that every aspect of mental and physical health deteriorates with age (but see McDaniel, Einstein, \& Jacoby 2008), these results provide exciting initial evidence that spontaneous retrieval processes that could support prospective memory remain intact with normal aging. However, the activation of the spontaneous retrieval process appears to "linger" in older adults, such that their inhibitory deficits cause them to continue to retrieve intentions that are finished or no longer relevant.

\section{References}

Anderson, M. C., Bjork, R. A., \& Bjork, E. L. (1994). Remembering can cause forgetting: Retrieval dynamics in long-term memory. Journal of Experimental Psychology: Learning, Memory, and Cognition, 20, 1063-1087.

Breneiser, J. E., \& McDaniel, M. A. (2006). Discrepancy processes in prospective memory retrieval. Psychonomic Bulletin \& Review, $13,837-841$.

Bunting, M. (2006). Proactive interference and item similarity in working memory. Journal of Experimental Psychology: Learning, Memory, and Cognition, 32, 183-196.

Cherry, K. E., \& LeCompte, D. C. (1999). Age and individual differences influence prospective memory. Psychology and Aging, 14, 60-76.

Cohen, A.-L., Dixon, R. A., \& Lindsay, D. S. (2005). The intention interference effect and aging: Similar magnitude of effects for young and old adults. Applied Cognitive Psychology, 19, 11771197.

Cohn, M., Emrich, S. M., \& Moscovitch, M. (2008). Age-related deficits in associative memory: The influence of impaired strategic retrieval. Psychology and Aging, 23, 93-103.

Craik, F. I. M. (1986). A functional account of age differences in memory. In F. Klix \& H. Hagendorf (Eds.), Human memory and cognitive capabilities: Mechanisms and performances (pp. 409422). Amsterdam: North-Holland.

Crovitz, H. F., \& Daniel, W. F. (1984). Measurements of everyday memory: Toward the prevention of forgetting. Bulletin of Psychonomic Society, 22, 413-414.

Darowski, E. S., Helder, E., Zacks, R. T., Hasher, L., \& Hambrick, D. Z. (2008). Age-related differences in cognition: The role of distraction control. Neuropsychology, 22, 638-644. 
De Frias, C. M., Dixon, R. A., \& Strauss, E. (2009). Characterizing executive functioning in older special populations: From cognitively elite to cognitively impaired. Neuropsychology, 23, 778-791.

Dempster, F. N. (1992). The rise and fall of the inhibitory mechanism: Toward a unified theory of cognitive development and aging. Developmental Review, 12, 45-75.

Einstein, G. O., \& McDaniel, M. A. (1990). Normal aging and prospective memory. Journal of Experimental Psychology: Learning, Memory, and Cognition, 16, 717-726.

Einstein, G. O., \& McDaniel, M. A. (2005). Prospective memory: Multiple retrieval processes. Current Directions in Psychological Science, 14, 286-290.

Einstein, G. O., McDaniel, M. A., \& Scullin, M. K. (in press). Prospective memory and aging: Understanding the variability. In N. Ohta \& M. Naveh-Benjamin (Eds.), Memory and Aging. Psychology Press.

Einstein, G. O., McDaniel, M. A., Thomas, R., Mayfield, S., Shank, H., Morrisette, N., et al. (2005). Multiple processes in prospective memory retrieval: Factors determining monitoring versus spontaneous retrieval. Journal of Experimental Psychology: General, 134, 327-342.

Golden, C. J. (1978). Stroop Color and Word Test: A manual for clinical and experimental uses. Chicago: Skoelting.

Grady, C. L., Spinger, M. V., Hongwanishkul, D., McIntosh, A. R., \& Winocur, G. (2006). Age-related changes in brain activity across the adult lifespan. Journal of Cognitive Neuroscience, 18, 227241.

Harrison, T. L., \& Einstein, G. O. (2010). Prospective memory: Are preparatory attentional processes necessary for a single focal cue? Memory \& Cognition, 38, 860-867.

Hasher, L., \& Zacks, R. T. (1988). Working memory, comprehension, and aging: A review and a new view. In G. H. Bower (Ed.), The Psychology of Learning and Motivation (Vol. 22, pp. 193-225). New York: Academic Press.

Hashtroudi, S., Johnson, M. K., \& Chrosniak, L. D. (1989). Aging and source monitoring. Psychology and Aging, 4, 106-112.

Henry, J. D., MacLeod, M. S., Phillips, L. H., \& Crawford, J. R. (2004). A meta-analytic review of prospective memory and aging. Psychology and Aging, 19, 27-39.

Hicks, J. L., Marsh, R. L., \& Russell, E. J. (2000). The properties of retention intervals and their effect on retaining prospective memories. Journal of Experimental Psychology: Learning, Memory, and Cognition, 26, 1160-1169.

Kliegel, M., Jager, T., \& Phillips, L. H. (2008). Adult age differences in event-based prospective memory: A meta-analysis on the role of focal versus nonfocal cues. Psychology and Aging, 23, 203208.

Knight, J. B., Meeks, J. T., Marsh, R. L., Cook, G. I., Brewer, G. A., \& Hicks, J. L. (2011). An observation on the spontaneous noticing of prospective memory event-based cues. Journal of Experimental Psychology: Learning, Memory, and Cognition, 37, 298-307.

Kučera, H., \& Francis, W. N. (1967). Computational analysis of present-day American English. Providence: Brown University Press.

Kvavilashvili, L., Kornbrot, D. E., Mash, V., Cockburn, J., \& Milne, A. (2009). Differential effects of age on prospective and retrospective memory tasks in young, young-old, and old-old adults. Memory, 17, 180-196.

Langenecker, S. A., Zubieta, J. K., Young, E. A., Akil, H., \& Nielson, K. A. (2007). A task to manipulate attentional load, set-shifting, and inhibitory control: Convergent validity and test-retest reliability of the parametric go/no-go test. Journal of Clinical and Experimental Neuropsychology, 29, 842-853.

Lustig, C., Hasher, L., \& Zacks, R. (2007). Inhibitory deficit theory: Recent developments in a "new view". In D. S. Gorfein \& C. M.
MacLeod (Eds.), The place of inhibition in cognition (pp. 145162). Washington: American Psychological Association.

Marsh, R. L., Hicks, J. L., \& Bink, M. L. (1998). Activation of completed, uncompleted, and partially completed intentions. Journal of Experimental Psychology: Learning, Memory, and Cognition, 24, 350-361.

Marsh, R. L., Hicks, J. L., \& Cook, G. I. (2006). Task interference from prospective memories covaries with contextual associations of fulfilling them. Memory \& Cognition, 34, 1037-1045.

Maylor, E. A. (1996). Age-related impairment in an event-based prospective-memory task. Psychology and Aging, 11, 74-78.

McDaniel, M. A., \& Einstein, G. O. (2000). Strategic and automatic processes in prospective memory retrieval: A multiprocess framework. Applied Cognitive Psychology, 14, S127-S144.

McDaniel, M. A., \& Einstein, G. O. (2007). Prospective memory: An overview and synthesis of an emerging field. Thousand Oaks: Sage.

McDaniel, M. A., \& Einstein, G. O. (in press). The neuropsychology of prospective memory in normal aging: A componential approach. Neuropsychologia

McDaniel, M. A., Einstein, G. O., \& Jacoby, L. L. (2008). New considerations in aging and memory: The glass may be half full. In F. I. M. Craik \& T. Salthouse (Eds.), The handbook of aging and cognition (3rd ed., pp. 251-310). New York: Psychology Press.

McDaniel, M. A., Guynn, M. J., Einstein, G. O., \& Breneiser, J. (2004). Cue-focused and reflexive-associative processes in prospective memory retrieval. Journal of Experimental Psychology: Learning, Memory, and Cognition, 30, 605-614.

McDaniel, M. A., \& Scullin, M. K. (2010). Implementation intention encoding does not automatize prospective memory responding. Memory \& Cognition, 38, 221-232.

Moscovitch, M. (1994). Memory and working with memory: Evaluation of a component process model and comparisons with other models. In D. L. Schacter \& E. Tulving (Eds.), Memory systems (pp. 269-310). Cambridge: MIT Press.

Naveh-Benjamin, M. (2000). Adult age differences in memory performance: Tests of an associative deficit hypothesis. Journal of Experimental Psychology: Learning, Memory, and Cognition, 26, 1170-1187.

Park, D. C., Lautenschlager, G., Hedden, T., Davidson, N. S., Smith, A. D., \& Smith, P. K. (2002). Models of visuospatial and verbal memory across the adult life span. Psychology and Aging, 17, 299-320.

Raven, J. C., Raven, J., \& Court, J. H. (1988). The Mill Hill vocabulary scale. London: Lewis.

Reitan, R. M. (1992). Trail making test: Manual for administration and scoring. Tucson: Reitan Neuropsychological Laboratory.

Scullin, M. K., \& McDaniel, M. A. (2010). Remembering to execute a goal: Sleep on it! Psychological Science, 21, 1028-1035.

Scullin, M. K., Einstein, G. O., \& McDaniel, M. A. (2009). Evidence for spontaneous retrieval of suspended but not finished prospective memories. Memory \& Cognition, 37, 425-433.

Scullin, M., Bugg, J., \& McDaniel, M. (2010a). Prospective memory and aging: Failing to remember or failing to forget? Paper presented at the 51st Annual Meeting of the Psychonomic Society, St. Louis, MO

Scullin, M. K., McDaniel, M. A., \& Einstein, G. O. (2010b). Control of cost in prospective memory: Evidence for spontaneous retrieval processes. Journal of Experimental Psychology: Learning, Memory, and Cognition, 36, 190-203.

Scullin, M. K., McDaniel, M. A., Shelton, J. T., \& Lee, J. H. (2010c). Focal/nonfocal cue effects in prospective memory: Monitoring difficulty or different retrieval processes? Journal of Experimental Psychology: Learning, Memory, and Cognition, 36, 736-749. 
Smith, R. E., \& Bayen, U. J. (2005). The effects of working memory resource availability on prospective memory: A formal modeling approach. Experimental Psychology, 52, 243-256.

Spieler, D. H., Balota, D. A., \& Faust, M. E. (1996). Stroop performance in healthy younger and older adults and in individuals with dementia of the Alzheimer's type. Journal of Experimental Psychology: Human Perception and Performance, 22, 461-479.

Stroop, J. R. (1935). Studies of interference in serial verbal reactions. Journal of Experimental Psychology, 18, 643-662.

Uttl, B. (2005). Measurement of individual differences: Lessons from memory assessment in research and clinical practice. Psychological Science, 16, 460-467.

West, R. (1996). An application of prefrontal cortex function theory to cognitive aging. Psychological Bulletin, 120, 272-292.
West, R., Herndon, R. W., \& Covell, E. (2003). Neural correlates of age-related declines in the formation and realization of delayed intentions. Psychology and Aging, 18, 461-473.

West, R., McNerney, M. W., \& Travers, S. (2007). Gone but not forgotten: The effects of cancelled intentions on the neural correlates of prospective memory. International Journal of Psychophysiology, 64, 215-225.

Whittlesea, B. W. A., \& Williams, L. D. (2001a). The discrepancyattribution hypothesis: I. The heuristic basis of feelings of familiarity. Journal of Experimental Psychology: Learning, Memory, and Cognition, 27, 3-13.

Whittlesea, B. W. A., \& Williams, L. D. (2001b). The discrepancyattribution hypothesis: II. Expectation, uncertainty, surprise, and feelings of familiarity. Journal of Experimental Psychology: Learning, Memory, and Cognition, 27, 14-33. 